\section{Clinical Vistas}

\section{A woman with orbital}

\section{myositis}

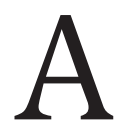

3I-year-old woman presented with a I-day history of a severe left-sided headache and left-eye pain of acuteonset. There was no history of trauma, and she was afebrile. The patient's symptoms were aggravated by movement of the eyes. She also described diplopia on all movements of the eyes. Examination revealed indurative edema of the left eyelid, and minimal conjunctival injection and mild proptosis of the left eye. Ocular movements were not limited. Laboratory test results were unremarkable. Post-septal orbital cellulitis was diagnosed, and the patient was given parenteral antibiotic therapy. Her symptoms did not improve, and her proptosis worsened over the next 36 hours. MRI of the orbits revealed thickening of the left medial rectus muscle (Fig. I, arrow) and stranding of the post-septal fat. Orbital myositis was considered, and parenteral steroid therapy was started. The patient's symptoms improved dramatically over the next 2 days, which confirmed the diagnosis.

Idiopathic orbital inflammation, or orbital inflammatory pseudotumour, is a non-neoplastic, non-infectious, spaceoccupying inflammatory lesion without identifiable local or systemic cause. The condition is called orbital myositis $\sim$ when it involves the extraocular muscles. It is the third most common orbital disorder, following thyroidassociated orbitopathy and lymphoproliferative disease, and accounts for about $5 \%$ of orbital disorders. ${ }^{1}$ Orbital myositis occurs mainly in young adults

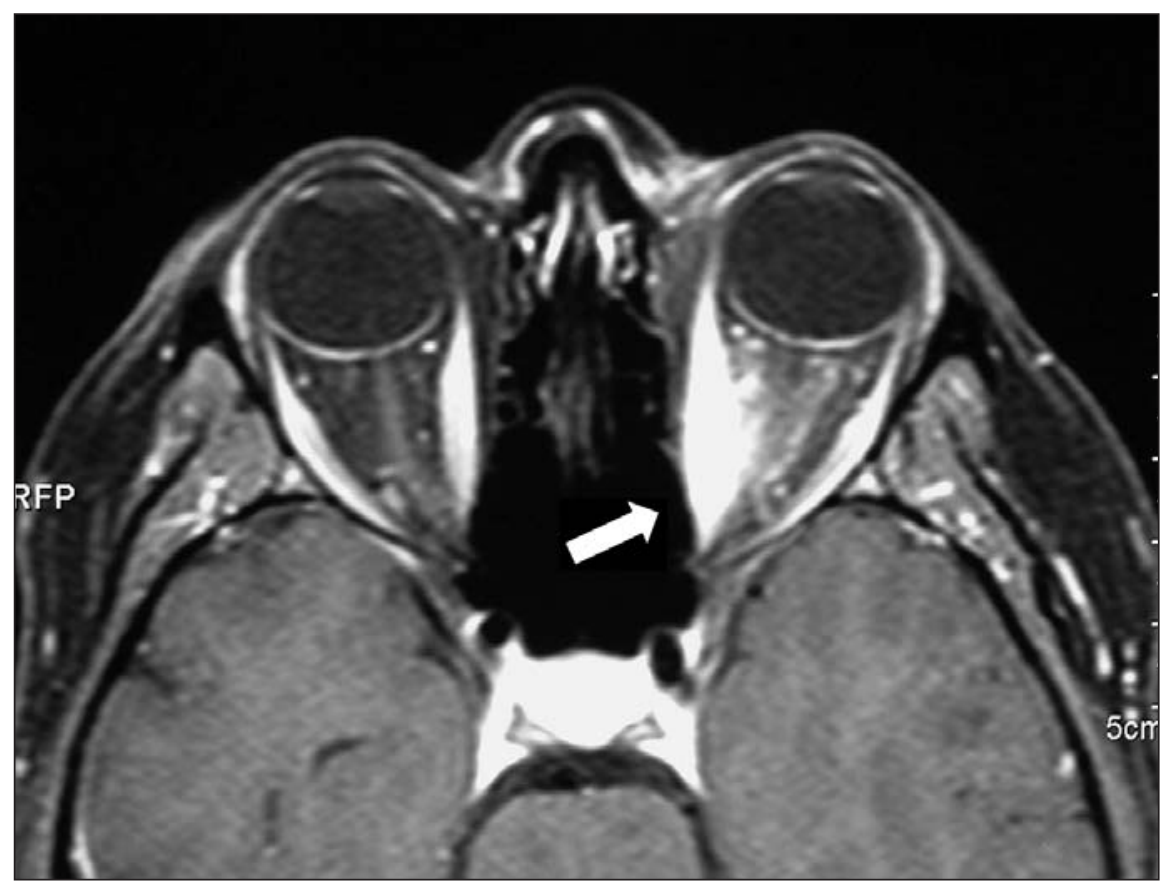

Fig 1: MRI revealing thickening of left medial rectus muscle (arrow) and stranding of post-septal fat in a woman with orbital myositis.

and typically presents with acute abnormal displacement of the eye anteriorly from the orbit (proptosis), conjunctival edema (chemosis) and limited extraocular movements, often unilateral. Headache, as occurred in our patient, is an uncommon presenting symptom and is often misdiagnosed as a cluster headache because of the associated inflammatory features. ${ }^{2}$ The differential diagnosis includes infection (orbital cellulitis, orbital abscess), thyroid ophthalmopathy, vasculitis, sarcoidosis, neoplasm and arteriovenous malformations. Although benign, orbital myositis can lead to oculomotor dysfunction and vision loss. Systemic corticosteroid therapy is the mainstay of treatment and induces a rapid and dramatic reversal of the inflammatory features; however, it is associated with a high rate of recurrence. ${ }^{3}$ A high index of suspicion and prompt radiographic imaging are key to early diagnosis and treatment.

\section{Chetan Shenoy}

Department of Internal Medicine

Guthrie/Robert Packer Hospital

Sayre, Pa.

\section{Sudhakar Sattur}

Department of Medicine

The University of Arizona College

of Medicine

Tucson, Ariz.

Competing interests: None declared.

\section{REFERENCES}

I. Weber AL, Romo LV, Sabates NR. Pseudotumor of the orbit: clinical, pathologic, and radiologic evaluation. Radiol Clin North Am 1999;37:15I-68.

2. Lee MS, Lessell S. Orbital myositis posing as cluster headache. Arch Neurol 2002;59:635-6.

3. Yuen SJ, Rubin PA. Idiopathic orbital inflammation: distribution, clinical features, and treatment outcome. Arch Ophthalmol 2003;I21:49I-9. 